\title{
1 Development of early maturing submergence-tolerant rice varieties for Bangladesh
}

3 Khandakar M. Iftekharuddaula ${ }^{\mathrm{a}^{*}}$, Helal U. Ahmed ${ }^{\mathrm{a}}$, Sharmistha Ghosal ${ }^{\mathrm{a}}, \mathrm{Al}$ Amin ${ }^{\mathrm{a}}$, Zakiah R. $^{2}$

4 Moni $^{\mathrm{a}}$, Bisnu P. Ray ${ }^{\mathrm{b}}$, Hirendra N. Barman ${ }^{\mathrm{a}}$, Muhammad A. Siddique ${ }^{\mathrm{a}}$, Bertrand C. Y. Collard ${ }^{\mathrm{c}}$,

5 Endang M. Septiningsih ${ }^{\mathrm{c}, 1, *}$

6

$7 \quad{ }^{a}$ Bangladesh Rice Research Institute, Gazipur 1701, Bangladesh

$8 \quad{ }^{\mathrm{b}}$ Bangladesh Rice Research Institute Regional Station, Rangpur, Bangladesh

$9 \quad{ }^{\mathrm{c}}$ International Rice Research Institute, DAPO Box 7777, Metro Manila, Philippines

$10{ }^{1}$ Present address: Department of Soil and Crop Sciences, Texas A\&M University, College

11 Station, TX 77843, USA

$13 *$ Corresponding authors: 
21 Flash flooding imparts adverse effect on rice production worldwide. Because of the needs for

22 multiple cropping and to avoid incidences of cold and diseases later in the season, early maturing

23 submergence tolerant varieties have been urgently needed in some rice producing areas. Marker-

24 assisted backcrossing (MABC) was used to introgress the submergence-tolerance SUB1 QTL

25 from BRRI dhan52 into a short-duration rice variety, BRRI dhan33. In this particular study, a

26 combination of foreground and phenotypic selection was performed during the $\mathrm{BC}_{1} \mathrm{~F}_{1}-\mathrm{BC}_{4} \mathrm{~F}_{1}$

27 stages, while the whole set of foreground, recombinant and background markers were used at the

$28 \mathrm{BC}_{4} \mathrm{~F}_{2}$ stage. At the final stage, the recovery of recipient parent genome ranged from 90.7 to

$2995.2 \%$ in $15 \mathrm{BC}_{4} \mathrm{~F}_{3}$ promising lines. The introgression sizes of the different Sub1 lines were

30 estimated to be around 2.4 to 5.6 Mb. The submergence tolerance of line BR9157-12-2-37-13-

$31 \quad 15-40$ was found to be the best, having $87.7 \%$ survival. The grain yield of the Sub1 lines was

32 also significantly higher compared with that of the original variety, BRRI dhan33, under both

33 flooded and non-flooded conditions in on-station and on-farm trials. The maximum grain yield

34 obtained from a BRRI dhan33-Sub1 line was $4.8 \mathrm{t} /$ ha under on-farm non-flooded conditions and

$353.8 \mathrm{t} / \mathrm{ha}$ under on-farm flooded conditions. The best selected Sub1 line may be released in the

36 future as a short-duration, submergence-tolerant high-yielding variety for flood-prone rainfed

37 areas in Bangladesh.

39 Keywords: Foreground and phenotypic selection; Marker-assisted backcrossing; SUB1 QTL;

40 Submergence tolerance 


\section{1. INTRODUCTION}

44 The total production of rice has plateaued over recent years, with the gradual decrease of rice

45 crop-growing area because of expansion of other crops, other enterprises and development of

46 infrastructure. The static production of rice is still attributable to the lack of suitable improved

47 cultivars for different agroclimatic conditions, particularly unfavorable ecosystems. Among the

48 rice-growing ecosystems, the rainfed lowland areas are the most challenging due to the

49 prevalence of many abiotic and biotic stresses. Submergence is the most important abiotic stress

50 in the rainfed lowland rice (RLR) ecosystem in Bangladesh. More than 2.0 $\mathrm{M}$ ha of land in

51 Bangladesh is affected by different types of floods (Iftekharuddaula et al. 2011). Submergence

52 can result in yield losses of up to $100 \%$ depending on different environmental and floodwater

53 conditions (Neeraja et al. 2007).

55 The SUB1 QTL on chromosome 9, which accounts for $70 \%$ of the phenotypic variation for

56 survival under submergence, has been fine-mapped, and the cluster of genes underlying the QTL

57 has been cloned (Xu et al. 1996; 2000; 2006). To enable more precise molecular breeding, a

58 number of gene-based and tightly-linked markers in this $S U B 1$ region have been developed

59 (Neeraja et al. 2007; Septiningsih et al. 2009; 2013). This QTL has successfully been

60 introgressed into a number of different varieties at the International Rice Research Institute

61 (IRRI) (Iftekharuddaula et al. 2011; Neeraja et al. 2007; Septiningsih et al. 2009; 2015). In a

62 relatively short time, some of these Sub1 varieties have had a profound impact. Bangladesh Rice

63 Research Institute (BRRI) has so far released two submergence-tolerant varieties ( BRRI dhan51

64 and BRRI dhan52) but the duration of these varieties becomes longer after flooding that 
65 flowering becomes affected by cold temperature stress. Hence, short-duration Sub1 varieties are 66 essential.

68 BRRI dhan33 is an early-maturing rainfed lowland rice variety with a 118-day growth duration.

69 This variety does not possess the submergence-tolerance QTL SUB1, hence, it is susceptible to 70 submergence stress. This study was performed to convert this early rainfed lowland rice variety

71 BRRI dhan33 into a submergence-tolerant type by incorporating SUB1 from BRRI dhan52,

72 using marker-assisted backcrossing (MABC). In order to conserve resources and simultaneously

73 select for other traits, a combination of marker-based and phenotypic selection was performed. It

74 is expected that the improved BRRI dhan33 line with submergence tolerance, BRRI dhan33-

75 Sub1, will be more adaptable in submergence-prone areas of Bangladesh and preferred by

76 farmers, particularly in the flash flood-affected northern parts of the country. This modified

77 MABC approach can be used for rapid trait conversion for programs with limited resources and 78 where low-cost phenotyping is available.

\section{MATERIAL AND METHODS}

\section{2.1. Planting materials and crossing scheme}

82 The experiments were carried out to introgress the $S U B 1$ locus into BRRI dhan33, an early

83 rainfed lowland rice variety and lodging tolerance. This variety was derived from the cross

84 BG388/BG367-4, with accession number BG850; it was released by BRRI in 1997. The yield

85 potential of this variety is 4.5 tons/ha. BRRI dhan52, the high-yielding, flash flood-tolerant,

86 rainfed lowland rice variety of Bangladesh, served as the $S U B 1$ donor parent (Pedigree:

87 BR11*3/IR40931-33-1-3-2). The pedigree number of this variety is IR85260-66-654-Gaz2. For 
the MABC scheme, BRRI dhan33 was crossed with BRRI dhan52 to obtain $\mathrm{F}_{1}$ seeds in T. aman

89 (transplanted aman season, July to December) of 2009 at the experimental farm of BRRI,

90 Gazipur. The $\mathrm{F}_{1}$ plants (and the following backcross generations) were confirmed through

91 morphological character comparison (i.e. leaf color, panicle emergence, tiller height and pattern,

92 flag leaf length, breadth, and attitude, etc.) with the parents, especially the female parent, BRR1

93 dhan33. The selected $\mathrm{F}_{1}$ plants were backcrossed with BRRI dhan33 to obtain a large number of

$94 \mathrm{BC}_{1} \mathrm{~F}_{1}$ seeds. Repeated backcrosses were then followed by marker-assisted selection to recover

95 the genetic background of BRRI dhan33 (Fig. 1).

96

97 2.2. Molecular marker genotyping and analysis

98 In MABC, one tightly-linked SSR marker (RM8300) and/or one gene-based insertion-deletion

99 (indel) marker (Sub1C173), two flanking SSR markers (RM296, RM23915) (Neeraja et al. 2007;

100 Septiningsih et al. 2009) and 84 background SSR markers (polymorphic markers identified

101 through a survey of 615 primers) (Table A.1) were used for foreground, recombinant and

102 background selection, respectively. DNA was extracted from young leaves of 14-day-old plants

103 following the mini-scale method (Zheng et al. 1995). SSR marker genotyping was carried out

104 following previously-used methods for the development of Sub1 varieties (Iftekharuddaula et al.

105 2011; Neeraja et al. 2007; Septiningsih et al. 2009).

106

107 The marker data was analyzed using the software Graphical Genotyper (GGT 2.0) (Van Berloo,

108 2008). The homozygous recipient allele, homozygous dominant allele and heterozygous allele

109 were scored as 'A', 'B' and 'H', respectively. The percentage of homozygous markers for

110 recipient parent $(\% \mathrm{~A})$ heterozygous markers $(\% \mathrm{R})$, were calculated. The introgression sizes in 
111 the six BRRI dhan33-Sub1 lines were determined using 23 SSR and indel primers in SUB1

112 region.

113

114 2.3. Phenotyping and adaptability test of newly developed Sub1-lines

115 Three BRRI dhan33-Sub1 introgression lines (bulked $\mathrm{BC}_{4} \mathrm{~F}_{3}$ lines), along with recipient parent

116 BRRI dhan33 and donor parent BRRI dhan52, were evaluated in the submergence tanks of the

117 BRRI farm during the $2013 \mathrm{~T}$. aman season. The population derived from plant no. 82 was

118 discarded due to poor agronomic performance and susceptibility to bacterial blight. The

119 experiment used an RCBD with three replications using standard management practices. Thirty-

120 day-old seedlings were transplanted at 2 seedlings /hill with a spacing of $25 \mathrm{~cm} \mathrm{x} 15 \mathrm{~cm}$. The

121 unit plot size was $5.4 \mathrm{~m} \times 10$ rows. Complete submergence stress was imposed at $15 \mathrm{~d}$ after

122 transplanting and maintained for $15 \mathrm{~d}$. The average depth of water was $100 \mathrm{~cm}$. The average water

123 temperature was $32^{\circ} \mathrm{C}$ and water $\mathrm{pH}$ was 7.2. Parameters, including grain yield (t/ha), along with

124 growth duration $(\mathrm{d})$, plant height $(\mathrm{cm})$, panicle length $(\mathrm{cm})$, effective tillers per hill, spikelet

125 fertility, thousand-grain weight (g) and survival percentage were recorded.

126

127 Furthermore, 15 plants were selected from three $\mathrm{BC}_{3} \mathrm{~F}_{4}$ bulk populations. These 15 Sub1

128 genotypes together with 3 susceptible checks: BRRI dhan33, BRRI dhan44 and BRRI dhan49;

129 and 5 tolerant checks: BRRI dhan51, BRRI dhan52, IR64-Sub1, Ciherang-Sub1 and FR13A-

130 were tested under controlled submergence in 2014. Fourteen-day-old seedlings were transplanted

131 in submergence tank. The spacing used was $25 \mathrm{~cm} \mathrm{x} 15 \mathrm{~cm}$ with 2 rows ( 25 hills/row). At $14 \mathrm{~d}$

132 after transplanting, the crop was exposed to complete submergence, maintaining a 100-cm water

133 depth for $14 \mathrm{~d}$. During the submergence period, the water in the tank was made turbid twice daily 
134 manually using clay soil and the light intensity in upper level (normal), mid-level (30 cm below

135 the water surface $)$ and lower level $(75 \mathrm{~cm}$ below the water surface $)$ of the tank were measured

136 using light meter (LI-250) (Table A.2). At $14 \mathrm{~d}$ after submergence, the water was drained. Data

137 for different parameters were taken following the methodologies described below:

138 Elongation $\%=100 *$ (height $5 \mathrm{~d}$ after desubmergence - height before submergence)/height

139 before submergence.

140 Percent increase in dry matter (DM) during submergence was calculated, taking destructive 141 samples of 5 plants before submergence and then $5 \mathrm{~d}$ after desubmergence. The samples were

142 dried in a vacuum oven at $72^{\circ} \mathrm{C}$ for $72 \mathrm{~h}$. The formula for calculating this parameter was:

$143 \%$ increase in $\mathbf{D M}=100 *(\mathrm{DM} 5 \mathrm{~d}$ after desubmergence $-\mathrm{DM}$ at submergence $) / \mathrm{DM}$ at

144 submergence.

145 Recovery ability and tolerance score: These were recorded at 5 and $30 \mathrm{~d}$ after desubmergence

146 on the basis of tillering ability, \% survival and vegetative growth following the IRRI (2002)

147 Standard Evaluation System, with slight modification (SES, Table A.3). The survival data was

148 recorded at $5 \mathrm{~d}$ after desubmergence using SES, with 1 being highly tolerant and 9 being highly

149 susceptible (Table A.4). Recovery status was also evaluated $30 \mathrm{~d}$ after de-submergence.

150 Survival $\%=100 *$ (number of surviving plants $5 \mathrm{~d}$ after desubmergence/total plants before 151 submergence)

152 Six submergence-tolerant high-yielding genotypes, along with two check varieties from IRRI 153 that are submergence tolerant and early, IR10F365 (IR 87439-BTN-145-2-1) and IR09F130 (IR 154 87107-47-2-1-1) were evaluated in five locations, including submergence-prone farmers' fields. 155 The experimental design was a RCBD with three replications. Standard management practices 156 for flooded and non-flooded conditions were carried out following Iftekharuddaula et al. (2015). 
157 A detailed evaluation of grain quality parameters was performed. The samples were milled raw 158 and analyzed for physicochemical properties. Milled rice recovery was determined by dehulling $159200 \mathrm{~g}$ rough rice in Satake Rice Mill, followed by 45 second polishing in a Satak Grain testing 160 Mill TM-5. Head rice recovery was determined by separating broken rice from milled rice by 161 hand. Milled rice recovery and head rice recovery were expressed as percentage of rough rice 162 and milled rice respectively. Grain length and breadth were measured by slide calipers. In 163 determining the size and shape, milled rice was first classified into three classes based on length, 164 long ( $>6 \mathrm{~mm}$ in length), medium (5-6 $\mathrm{mm}$ in length) and short ( $<5 \mathrm{~mm}$ in length). Then again 165 classified into three classes according to the ratio of length to breadth, slender (ratio>3.0), bold 166 (ratio 2-3) and round (ratio<2.0). Amylose content was determined according to procedure of 167 Little et al. (1958). Protein content was determined by micro Kjeldahl method (AOAC, 1970). 168 Elongation ratio was calculated by measuring the length of cooked and uncooked milled rice by 169 slide calipers. Volume of cooked and uncooked milled rice was measured by water displacement 170 method. Data presented in the tables are the mean of three replications.

171 The brief definition of each grain quality parameters are given as follows:

172 Milling recovery: Milling recovery is the estimate of the quantity of total milled rice that can be 173 produced from a unit of rough rice. It is generally expressed as a percentage.

174 Head rice yield: Head rice yield is the estimate of the quantity of whole grains (head rice) that 175 can be produced from a unit of rough rice. It is generally expressed as a percentage.

176 Appearance: Grain appearance refers to the size and shape of the kernel and translucency and 177 chalkiness of the grain.

178 Chalkiness: Chalkiness is the white portion of the rice grain which is formed on the dorsal side, 179 ventral side and in the center of the grain caused by temporal reduction in starch biosynthesis 
180 during osmotic adjustment. The starch granules in the chalky areas are less densely packed than 181 translucent areas. Therefore, the chalky areas are not as hard as the translucent areas and the 182 grains with chalkiness are more prone to breakage during milling.

183 Alkali spreading value: A test for estimating the gelatinization temperature of starch utilizing a 184 seven point scale of the degree of spreading of milled rice grains in potassium hydroxide 185 solution. A low alkali spreading value (2-3) indicates a high gelatinization temperature implying 186 a longer cooking time; a high value (6-7) indicates low gelatinization temperature and shorter 187 cooking time.

188 Amylose: Amylose is a helical polymer made of $\alpha$-D-glucose units, bound to each other through $189 \alpha(1 \rightarrow 4)$ glycosidic bonds. This polysaccharide is one of the two components of starch, making 190 up approximately $20-30 \%$ of the structure. Amylose content correlates negatively with taste 191 panel scores for cohesiveness, tenderness, color, and gloss of boiled rice.

192 Protein: Large molecules composed of one or more chains of amino acids in a specific order 193 determined by the base sequence of nucleotides in the DNA coding for the protein.

194 Cooking time: Cooking time is largely determined by the properties of the starch that makes up $19590 \%$ of milled rice. Gelatinization temperature, amylose content, and gel consistency are the 196 important starch properties that influence cooking duration.

197 Elongation ratio: Elongation ratio is defined as the ratio of length of 10 sound cooked rice 198 grains to the length of the 10 sound milled rice grains. Length of cooked rice and milled rice is 199 measured by slide calipers.

200 Imbibition ratio: Imbibition or volume expansion ratio is defined as ratio of the volume of 100 201 sound cooked rice grains to volume of 100 sound milled rice grains. Volume of cooked and 202 milled rice is measured by water displacement. 


\section{RESULTS}

\subsection{BRRI dhan33-Sub1 development}

206 A total of $48 F_{1}$ seeds were produced. The $F_{1}$ plants were selected based on morphological 207 characters and the selected $\mathrm{F}_{1} \mathrm{~S}$ were backcrossed with BRRI dhan33. A total of $137 \mathrm{BC}_{1} \mathrm{~F}_{1}$

208 plants were produced from the five best plants (plant numbers 12, 9, 11, 13 and 6), which were 209 selected after foreground and morphological selection. Then $745 \mathrm{BC}_{2} \mathrm{~F}_{1}$ seeds were produced

210 through subsequent backcrossing of these 5 best plants. In the $\mathrm{BC}_{2} \mathrm{~F}_{1}$ generation, the 3 best plants 211 were selected based on foreground and morphological selection, from which $304 \mathrm{BC}_{3} \mathrm{~F}_{1}$ seeds 212 were produced.

214 In the $\mathrm{BC}_{3} \mathrm{~F}_{1}$ generation, foreground selection was performed for 94 phenotypically selected 215 plants using RM8300. Out of these 94 plants, 32 were heterozygous (Score H), 39 showed fixed 216 recipient alleles (susceptible allele; Score A) and 4 showed fixed donor alleles (resistant allele;

217 Score B) for the SUB1 locus. Furthermore, 11 plants were phenotypically selected based on 218 morphological criteria from 32 plants possessing the submergence tolerance QTL ( $\mathrm{H}$ allele), and 219 additional backcrossing was conducted to recover the recipient parent genome. A total of 716

$220 \mathrm{BC}_{4} \mathrm{~F}_{1}$ seeds were produced from $11 \mathrm{BC}_{3} \mathrm{~F}_{1}$ plants, but only 14 plants survived in the main field 221 due to cold injury. Foreground selection was performed using SUB1C173. Only one plant that 222 was homozygous for SUB1 allele and which phenotypically resembled BRRI dhan33 was self223 pollinated to produce the $\mathrm{BC}_{4} \mathrm{~F}_{2}$ seeds. In the $\mathrm{BC}_{4} \mathrm{~F}_{2}$ generation, foreground selection was

224 performed in 94 plants that had been selected based on morphological criteria out of 304 plants.

225 Out of these 94 plants, 35 were heterozygous, 53 showed fixed recipient alleles and 4 showed 
226 fixed donor alleles for RM8300. All of the plants had fixed donor alleles for Sub1C173. The 4

227 plants with the 'B' score for both markers were subjected to recombinant and background

228 selection. Recombinant selection was performed in the $\mathrm{BC}_{4} \mathrm{~F}_{2}$ generation. The scores for all

229 flanking markers were ' $\mathrm{B}$ ', which indicated that the plants had fixed donor alleles containing

$230 S U B 1$ in the $\mathrm{BC}_{4} \mathrm{~F}_{2}$ generation of this plant.

232 Background selection was performed in 4 segregants possessing the fixed donor alleles of the 233 SUB1 QTL and the three flanking markers in the $\mathrm{BC}_{4} \mathrm{~F}_{2}$ generation. A total of 47 background 234 markers were used. All the 4 plants possessed homozygous recipient alleles for 44 markers and 235 homozygous donor alleles for two markers, RM8300 and Sub1C173. Two plants, plant numbers 23615 and 17, had homozygous donor alleles for RM211. The percentage of recipient alleles

237 recovered in the two best plants was 91.43 and $93.47 \%$.

239 Background selection was again carried out for the 15 selected lines in the $\mathrm{BC}_{4} \mathrm{~F}_{3}$ generation, 240 which possessed the fixed donor alleles for SUB1. A total of 84 background markers were used. 241 The maximum number of background markers used was 11 each for chromosomes 1 and 3 , and 242 the minimum number of background markers used was 4 for chromosomes 5, 7, 8 and 12. This

243 low number of polymorphic markers on these particular chromosomes might be due to the level 244 of genetic similarity between BRRI dhan33 and BRRI dhan 52. Here, 8 lines-BR9157-12-2-37245 13-15-25, BR9157-12-2-37-13-15-30, BR9157-12-2-37-13-15-35, BR9157-12-2-37-13-15-40, 246 BR9157-12-2-37-13-15-42, BR9157-12-2-37-13-17-27, BR9157-12-2-37-13-17-39 and

247 BR9157-12-2-37-13-17-41- possessed homozygous recipient alleles for 80 background 248 markers for non-carrier chromosomes; homozygous donor alleles for RM296, Sub1C173, 
249 RM8300 and RM23915 for chromosome 9 (all of these referred to as Type A). Six plants, with

250 the designation BR9157-12-2-37-13-17-32, BR9157-12-2-37-13-17-36, BR9157-12-2-37-13-71-

251 26, BR9157-12-2-37-13-71-32, BR9157-12-2-37-13-71-38 and BR9157-12-2-37-13-71-41 had

252 homozygous recipient alleles for 78 background markers for non-carrier chromosomes;

253 homozygous donor alleles for RM296, Sub1C173, RM8300, RM23915, RM3912 and RM1896

254 for chromosome 9 (all of these referred to as Type B). The percentage of recipient alleles of lines

255 ranged from 90.7 to $95.2 \%$ (Table A.5). In the best selected line, BR9157-12-2-37-13-15-25, all

256 background markers used were identical to the recipient type, thus, the recipient genome

257 percentage is $100 \%$ (Fig. 2).

258

259 3.2. Phenotyping and adaptability test of newly developed Sub1 lines

260 The grain yield and survival of all the introgression lines $\left(\mathrm{BC}_{3} \mathrm{~F}_{4}\right.$ bulk lines) were significantly

261 higher than the recipient parent BRRI dhan33, indicating satisfactory agronomic performance

262 and successful introgression of submergence tolerance in the new lines (Fig. A.1). Under

263 controlled submergence conditions, the grain yields of the introgression lines were 1.24 to 1.71

264 t/ha higher than that of the recipient parent, which were statistically significant. The newly

265 introgressed BRRI dhan33-Sub1 lines are similar to BRRI dhan33 with respect to the growth

266 duration, effective tillers per plant, filled and unfilled grains per panicle and spikelet fertility.

267 However, the new Sub1 lines have better survival rate, 1000 grain weight, and panicle length

268 (Table 1).

269

270 All of the 15 (plant selections from bulk population) genotypes were compared with the tolerant

271 genotypes BRRI dhan51, BRRI dhan52, IR64-Sub1, Ciherang-Sub1 and FR13A, and the 
272 susceptible genotypes of BRRI dhan33, BRRI dhan44 and BRRI dhan49. Among the tested 273 genotypes, 3 lines (BR9157-12-2-37-13-71-41, BR9157-12-2-37-13-15-30 and BR9157-12-2-

274 37-13-15-40; Table 2), had good survival and excellent recovery; and were non-elongating (11.4$27511.5 \%$ elongation). The elongation ranged from 0.8 to 99.4 , and \% survival from 48.6 to 94.7 in 276 the tested genotypes. The increase in dry matter in the selected three genotypes ranged from 6.7-

277 114.2, and SES score was 3. The rest of the Sub1 introgression lines were as tolerant as the 278 tolerant checks but superior than the susceptible checks after $14 \mathrm{~d}$ of complete submergence. The 279 rest of the Sub1 lines were also non-elongating types with survival scores ranging from 4 to 5 .

281 Out of the 23 markers in the Sub1 region, 12 markers were polymorphic between BRRI dhan 33 282 and BRRI dhan52. Based on the alleles of six gene-based markers and ten additional 283 polymorphic markers within the Sub1 QTL region, the size of donor introgression among BRRI 284 dhan33-Sub1 lines was 5.6 Mb, with the exception for BR 9157-12-2-37-13-71-4, which was $285 \sim 2.4 \mathrm{Mb}$. The presence of SUB1 genes among those individuals was also confirmed (Table A.6). 286 The different alleles of SUB1BC2 and RM23902 among BRRI dhan33-Sub1 lines are shown as 287 an example (Fig. A.2).

289 The milling recovery and head rice yield of BRRI dhan33-Sub1 lines ranged from 70.7 to $71.9 \%$ 290 and 51.2 to $65.6 \%$, respectively, whereas these were 70.5 and $49.0 \%$, respectively, in BRRI 291 dhan33. Chalkiness was categorized as $\mathrm{Wb}_{5}$ (10-20\% chalkiness) in all the BRRI dhan33-Sub1 292 lines, but it was $\mathrm{Wb}_{9}(>20 \%$ chalkiness) in BRRI dhan33. Length to breadth ratio and alkali 293 spreading value ranged from 2.1 to 2.4 and 3.5 to 5.0, respectively, in BRRI dhan33-Sub1 lines, 294 and the values were 2.1 and 4.5, respectively, in BRRI dhan33. Amylose content of BRRI 
dhan33-Sub1 lines and BRRI dhan33 was $>26 \%$, hence, these values can be categorized as high

296 amylose content. Protein was slightly higher in BRRI dhan33-Sub1 lines, ranging from 7.4 to

$2978.5 \%$, whereas it was $6.6 \%$ in BRRI dhan33. The cooking time was more or less similar among

298 BRRI dhan33-Sub1 (18.3-19.3 min) lines compared with BRRI dhan33 (20.0 min). The

299 elongation ratio was a bit higher in BRRI dhan33-Sub1 lines (1.4-1.8) compared with that in

300 BRRI dhan33 (1.3) and the imbibition ratio was similar in BRRI dhan33-Sub1 lines (2.4-3.1)

301 compared with that in BRRI dhan33 (2.8) (Table 3).

302

303 There were no flash floods in three trials conducted at Gazipur, Nilphamari and Kawnia. There

304 were no significant differences between BRRI dhan33-Sub1 lines and BRRI dhan33 with respect

305 to growth duration (d), plant height (cm), panicles/plant, filled grains/panicle and sterility $(\%)$.

306 Moreover, all BRRI dhan33-Sub1 lines produced significantly higher grain yield than BRRI

307 dhan33. Importantly, two breeding lines, BR9157-12-2-37-13-71-32 and BR9157-12-2-37-13-

308 15-30, produced $4.8 \mathrm{t} / \mathrm{ha}$ of grain yield, which was significant higher $(0.8 \mathrm{t} / \mathrm{ha})$ than the grain

309 yield of BRRI dhan33 (Table 4) under control conditions.

310

311 At Lalmonirhat, there were two flash flood events for 15 and 9 d during T. aman 2014 (Table

312 A.7). There was a period of $23 \mathrm{~d}$ between the two flash floods, and the average depth of flood

313 water was $110-120 \mathrm{~cm}$. Sixteen d of controlled submergence with a water depth of $80 \mathrm{~cm}$ was

314 imposed at BRRI, Rangpur. The average performance of the breeding lines under flooded

315 conditions reflected that growth durations ranged from 142 to $143 \mathrm{~d}$ among BRRI dhan33-Sub1

316 lines, whereas it was $143 \mathrm{~d}$ in BRRI dhan33. Four BRRI dhan33-Sub1 lines showed similar

317 values compared with BRRI dhan33, with respect to plant height, panicles/plant and sterility. 
318 The same breeding lines showed significantly higher values than BRRI dhan33 for filled

319 grains/panicle and \% survival. Moreover, BRRI dhan33-Sub1 lines produced 2.2-2.3 t/ha more

320 grain yield than the original recipient variety, BRRI dhan33, under flooded conditions, with the

321 highest grain yield (3.8 t/ha) obtained from 2 lines, BR9157-12-2-37-13-17-27 and BR9157-12-

322 2-37-13-15-25 (Table 5).

324 4. Discussion

325 In this study, SUB1 was introgressed into BRRI dhan33 to develop a short-duration,

326 submergence-tolerant rice variety using MABC. We did not perform background selection from

327 the very beginning as was previously done (Iftekharuddaula et al., 2011; Neeraja et al. 2007;

328 Septiningsih et al. 2009), but used a combination of foreground marker and phenotypic selection

329 and several rounds of additional backcrossing instead, in order to reduce resources and more

330 importantly to allow generating more recombinations to break any negative linkage drags which

331 enables selecting the best plants that closely resembled the recipient parent, yet with more

332 beneficial attributes such as higher yield or other desirable traits. Although recombinant selection

333 was practiced using three flanking markers in the advanced backcross generation, the

334 introgression size in the vicinity of SUB1 in BRRI dhan33-Sub1 lines was around 2.4 to $5.6 \mathrm{Mb}$.

335 The previous Sub1 line introgression sizes ranged from $\sim 0.8$ to $8 \mathrm{Mb}$ (Iftekharuddaula 2011;

336 Neeraja et al. 2007; Septiningsih et al., 2009; 2015). Nonetheless, and as for the previous Sub1

337 lines, the ultimate phenotype of BRRI dhan33-Sub1 lines was not affected with respect to

338 agronomic performance. In addition, the donor of this 'second generation' of Sub1 line was

339 BRRI dhan52, a variety that possesses high yield and desirable agronomic traits. In conventional

340 backcrossing, large donor segments are likely to be introgressed in the carrier chromosome 
341 (Young and Tanksley 1989) and, in this approach, a large donor segment has been inherited from

342 the carrier chromosome due to the lack of recombinant selection done in early backcross

343 generations. Young and Tanksley (1989) also pointed out that the donor genes on the carrier

344 chromosome were the most difficult to eliminate, and could persist long after the donor genome

345 content of non-carrier chromosomes has returned to approximately zero if no selection using

346 markers was applied. Since the donor parent was an improved genotype, this large introgression

347 did not cause any negative effect on the phenotype of BRRI dhan33-Sub1 lines.

349 In background selection, 84 markers spaced at an average distance of $21 \mathrm{cM}$ were used in the

350 advanced backcross generations in order to recover the homozygous recipient genetic

351 background of BRRI dhan33. Background selection was postponed in the early backcross

352 generations in order to make the marker genotyping less labour-intensive. This approach is

353 applicable for resource-poor countries using SSR markers for genotyping.

355 Submergence tolerance of the newly developed BRRI dhan33-Sub1 lines was found to be

356 superior to that of the recipient parent, including some agronomic parameters. In term of survival

357 rate and recovery score, BR9157-12-2-37-13-15-40, BR9157-12-2-37-13-15-30, and BR9157-

358 12-2-37-13-71-41 are among the three best lines (Table 2). Grain yields of BRRI dhan33-Sub1

359 lines were significantly higher compared to that of the original recipient variety BRRI dhan33

360 under both flooded and non-flooded conditions (Table 4 and 5). The significantly higher grain

361 yield of BRRI dhan52, in comparison with that of the recurrent parent variety BR11 under

362 controlled submergence conditions, was reported by Iftekharuddaula et al. (2015). The original

363 variety, BRRI dhan33 produced 4.0 t/ha grain yield under on-farm non-flooded condition while 
364 under on-farm flooded condition the variety produced $1.5 \mathrm{t} / \mathrm{ha}$ grain yield. The maximum grain

365 yield obtained from a BRRI dhan33-Sub1 line was 4.8 t/ha under on-farm non-flooded

366 conditions and $3.8 \mathrm{t} / \mathrm{ha}$ under on-farm flooded conditions. However, since the results of the

367 screening were not available yet by the time of the on-farm trials were conducted, not all the best

368 lines can be included in these trials due to limited resources. To some extent, the lower grain

369 yield of BRRI dhan33-Sub1 lines under both flooded and non-flooded conditions was associated

370 with the occurrence of bacterial blight and sheath rot diseases (data not shown). However, the

371 amount of grain yield advantages over the original recurrent parent (0.8-2.3 t/ha) was

372 encouraging. Additional trials will be conducted in the future to further test these lines. The

373 selected BRRI dhan33-Sub1 lines may be used in participatory variety selection trials for release

374 as a variety or as a parent to further develop high-yielding short-duration, submergence-tolerant

375 and disease resistant varieties through conventional and molecular breeding. The

376 physicochemical properties of BRRI dhan33-Sub1 lines were more or less similar to the

377 recurrent parent BRRI dhan33. Iftekharuddaula et al. (2011) also reported similar types of grain

378 physicochemical properties in BR11-Sub1 and in the original recurrent parent, BR11.

380 The growth duration of BRRI dhan33-Sub1 lines was around 140-143 d after two weeks of

381 controlled submergence stress, as well as under two natural occurrences of flash floods of $24 \mathrm{~d}$.

382 Although the growth duration was delayed by around $20 \mathrm{~d}$ compared with the growth duration

383 (119 d) of BRRI dhan33 under non-flooded conditions, it could still be possible to cultivate rabi

384 (winter) crops after harvesting BRRI dhan33-Sub1 lines even after multiple flash floods. Again,

385 the growth duration of BRRI dhan52, a submergence-tolerant high-yielding variety developed

386 earlier (Iftekharuddaula et al. 2015), was found to be around $157 \mathrm{~d}$, which was $17 \mathrm{~d}$ later than 
387 BRRI dhan33-Sub1 lines. The delayed growth duration of BRRI dhan52 creates a problem in

388 fitting this variety to some cropping sequences. The scenarios become worse when there are

389 multiple flash floods, which often occur in Bangladesh. After multiple flash flood events, the

390 duration of BRRI dhan52 is further delayed that it is affected by cold stress at the reproductive

391 phase (unpublished data, K. M. Iftekharuddaula). These problems are now partially solved by

392 introgressing SUB1 into the early, high-yielding rainfed lowland variety, BRRI dhan33.

393 However, BRRI dhan52 produced around 2.0 ton more grain yield than BRRI dhan33-Sub1 lines

394 implicating necessity of this variety in the land type where multiple flash flood does not occur

395 and where farmers do not need early rabi crops.

396

397 In summary, by combining foreground selection and morphological phenotyping from the very

398 beginning of the MABC process, while delaying the background selection until the last round,

399 we successfully developed early-maturing submergence tolerant rice lines, BRRI dhan33-Sub1,

400 with significantly higher yield compared to the original recurrent parent, BRRI dhan 33 , under

401 both flooded and non-flooded conditions of on-station and on-farm trials. It is hoped that one or

402 two of the best BRRI dhan33-Sub1 lines could soon be released in the flood-prone areas,

403 especially those that in need of short duration varieties due to the onset of other abiotic and biotic

404 stresses late in the planting season. These improved lines could help improve the livelihood of

405 farmers in submergence-prone areas of Bangladesh.

406

407

408 ACKNOWLEDGMENT 
409 This work was financially supported by the BAS Submergence Project (LI 12) under the BAS

410 USDA PALS program, the Integrated Agricultural Productivity Project (IAPP) funded by the

411 Global Agriculture and Food Security Program (GAFSP) and the Stress Tolerant Rice for Africa

412 and South Asia (STRASA) Project funded by the Bill \& Melinda Gates Foundation (BMGF).

414 REFERENCES

415 AOAC. 1970: Association of Official Agricultural Chemists. Methods of analysis, 11th edition 416 DC. P.585.

417 Iftekharuddaula, K. M., M. A. Newaz, M. A. Salam, H. U. Ahmed, M. A. A. Mahbub, E. M. Septiningsih, B. C. Y. Collard, D. L. Sanchez, A. M. Pamplona, and D. J. Mackill, 2011:

Iftekharuddaula, K. M., H. U. Ahmed, S. Ghosal, Z. R. Moni, A. Amin and M. S. Ali, 2015: Rapid and high-precision marker assisted backcrossing to introgress the SUB1 QTL into Development of New Submergence Tolerant Rice Variety for Bangladesh Using Marker-

424 IRRI. 2002. Standard Evaluation System for rice. Int. Rice Res. Inst., Los Baños, Philippines. 425 Juliano, B.O., 1971: A simplified assay for milled rice amylose. Cereal Sci. Today 16,334-338, $426 \quad 340-360$.

427 Little, R.R., G.B. Hiller and E.H. Daw Son., 1958: Differential effect of dilute alkali on 25 varieties of milled white rice. Cereal Chem. 35, 111-126.

429 Neeraja, C. N., R. M. Rodriguez, A. Pamplona, S. Heuer, B. C. Y. Collard, E. M. Septiningsih, 430 G. Vergara, D. Sanchez, K. Xu, A. M. Ismail, and D. J. Mackill, 2007: A marker-assisted 
backcross approach for developing submergence-tolerant rice cultivars. Theor. Appl. Genet. 115, 767-776.

433 Septiningsih, E. M., B. C. Y. Collard, S. Heuer, J. Bailey-Serres, A. M. Ismail, and D. J. Mackill, 434 2013: Applying genomics tools for breeding submergence tolerance in rice. In: R. K. 9-30.

Septiningsih, E. M., N. Hidayatun, D. L. Sanchez, Y. Nugraha, J. Carandang, A. M. Pamplona, Varshney and R. Tuberosa (eds). Translational genomics for crop breeding: Volume 2 -

Septiningsih, E. M., A. M. Pamplona, D. L. Sanchez, C. N. Neeraja, G. V. Vergara, S. Heuer, A. B. C. Y. Collard, A. M. Ismail, and D. J. Mackill, 2015: Accelerating the development of new submergence tolerant rice varieties: the case of Ciherang-Sub1 and PSB Rc18-Sub1 Euphytica 202, 259-268. M. Ismail, and D. J. Mackill, 2009: Development of submergence tolerant rice cultivars: the Subl locus and beyond. Ann. Bot. 103, 151-160.

Temnykh, S., G. DeClerck, A. Lukashova, L. Lipovich, S. Cartinhour, and S. McCouch, 2001: Computational and experimental analysis of microsatellites in rice (Oryza sativa L.): Frequency, length variation, transposon associations, and genetic marker potential. Genome Res. 11, 1441-1452.

Van Berloo, R., 2008: GGT 2.0: Versatile software for visualization and analysis of genetic data. Journal of Heredity 99, 232-236.

Xu, K., and D. J. Mackill, 1996: A major locus for submergence tolerance mapped on rice chromosome 9. Mol. Breeding 2,219-224. 
474 published map of Temnykh et al. (2001). Genet.77, 353-359. Philippines, 1-24.

\section{Figure legends}

Xu, K., X. Xia, T. Fukao, P. Canlas, R. M. Rodriguez, S. Heuer, A. I. Ismail, J. B. Serres, P. C. Ronald, and D. J. Mackill, 2006: SublA is an ethylene response factor-like gene that confers submergence tolerance to rice. Nature 442, 705-708.

Xu, K., X. Xu, P. C. Ronald, and D. J. Mackill, 2000: A high-resolution linkage map in the vicinity of the rice submergence tolerance locus Sub1. Mol. Gen. Genet. 263, 681-689.

Young, N. D., and S. D. Tanksley, 1989: RFLP analysis of the size of chromosomal segments retained around the Tm-2 locus of tomato during backcross breeding. Theor. Appl.

Zheng, K., N. Huang, J. Bennett, and G.S. Khush, 1995: PCR-based marker-assisted selection in rice breeding. International Rice Research Institute (IRRI), Los Baños, Laguna,

Figure 1. Marker assisted backcrossing scheme used indicating "Foreground and Phenotypic" selection steps. The number of plants to develop BRRI dhan33-Sub1 lines at each step is shown.

Figure 2. Graphical genotype of the selected best line. BR9157-12-2-37-13-17-25 was selected as the best genotype of the $\mathrm{BC}_{4} \mathrm{~F}_{3}$ generation. The black coloured regions on the chromosomes indicated a homozygous region for the recipient genome, whereas the grey coloured regions indicated the fixed donor allele regions. The distances are represented in $\mathrm{cM}$ based on the 475 
478 Table A.1. List of polymorphic markers of all 12 chromosomes used for background selection in 479 the development of BR dhan33-Sub1 lines.

481 Table A.2. Range of light intensity, $\mathrm{pH}$ and temperature of water during submergence period to 482 test the performance of submergence-tolerant lines along with selected references and checks 483 under non-flooded conditions, BRRI, Gazipur, T. aman 2014.

Table A.3. Criteria for recovery status after submergence stress. Recovery data was taken $30 \mathrm{~d}$ 486 after submergence.

Table A.4. Modified Standard evaluation system (SES) for survival after submergence. The 489 survival data was taken 5 d after submergence.

491 Table A.5. Results of background selection, Observational Trial $\left(\mathrm{BC}_{4} \mathrm{~F}_{3}\right.$ generation), T. Aman

492 2013. Type A refers to the eight lines possessing homozygous recipient alleles for 80

493 background markers for non-carrier chromosomes; homozygous donor alleles for RM296,

494 Sub1C173, RM8300 and RM23915 for chromosome 9. Type B refers to the six lines had

495 homozygous recipient alleles for 78 background markers for non-carrier chromosomes;

496 homozygous donor alleles for RM296, Sub1C173, RM8300, RM23915, RM3912 and RM1896

497 for chromosome 9. 
498 Table A.6. Different alleles of the Sub1-region markers among the BRRI dhan33-Sub1 lines. 'A'

499 represents the recipient's allele, BRRI dhan 33; 'B' represents the donor's allele, BRRI dhan52.

500

501 Table A.7. Status of flash flood at different locations of Bangladesh in T. aman 2014.

502

503 Figure A.1. Survival of BRRI dhan33-Sub1 line (BR9157-12-2-37-13-17) and BRRI dhan33

504 after $16 \mathrm{~d}$ of controlled submergence at BRRI, Gazipur, T. aman 2013. The survival of BRRI

505 dhan33 (recurrent parent check) was $22.1 \%$ whereas that of BRRI dhan33-Sub1 line (BR9157-

$506 \quad 12-2-37-13-17)$ was $88.9 \%$.

507

508 Figure A.2. Examples of different alleles of SUB1BC2 and RM23902 among the BRRI dhan33-

509 Sub1 lines. 'A' refers to BRRI dhan33, the recurrent parent's alleles, while 'B' refers to BRRI

510 dhan52, the donor parent's allele. It showed that all the BRRI dhan33-Sub1 lines already have

511 fixed donor alleles.

512 
Table 1. Performance of BRRI dhan33-Sub1 under submergence in T. aman 2013 season at BRRI, Gazipur. Data were means of three replicates. Duration of flooding was $14 \mathrm{~d}$. The survival data was taken at $5 \mathrm{~d}$ after de-submergence and recovery status was evaluated at $30 \mathrm{~d}$ of desubmergence.

\begin{tabular}{|c|c|c|c|c|c|c|c|c|c|}
\hline $\begin{array}{l}\text { Sl } \\
\#\end{array}$ & Designation & $\begin{array}{l}\mathbf{P H}^{\mathrm{a}} \\
(\mathbf{c m})\end{array}$ & $\begin{array}{c}\mathbf{G D}^{\mathbf{b}} \\
\text { (days) }\end{array}$ & $\begin{array}{l}\mathbf{P L}^{\mathrm{c}} \\
(\mathrm{cm})\end{array}$ & $\mathbf{E T}^{\mathrm{d}}$ & SFT $^{\mathbf{e}}$ & $\begin{array}{c}\text { TGW } \\
(\mathrm{g})\end{array}$ & $\begin{array}{c}\text { Survival } \\
\%\end{array}$ & $\begin{array}{c}\mathbf{G Y}^{\mathbf{g}} \\
(\mathbf{t} / \mathbf{h a})\end{array}$ \\
\hline 1 & BR9157-12-2-37-13-15 & 107.3 & 140 & 26.3 & 14.9 & 78.8 & 27.6 & 84.6 & 3.01 \\
\hline 2 & BR9157-12-2-37-13-17 & 108.1 & 141 & 27.3 & 13.9 & 74.8 & 28.4 & 88.9 & 3.44 \\
\hline 3 & BR9157-12-2-37-13-71 & 106.3 & 139 & 26.7 & 13.5 & 72.7 & 28.2 & 83.0 & 2.97 \\
\hline 4 & BRRI dhan33 (Ck) & 103.7 & 138 & 23.2 & 15.1 & 73.2 & 25.5 & 22.1 & 1.73 \\
\hline 5 & BRRI dhan52 (Ck) & 110.7 & 157 & 24.7 & 15.6 & 85.2 & 27.6 & 97.5 & 4.95 \\
\hline \multicolumn{2}{|c|}{$\operatorname{LSD}(0.05)$} & 3.58 & 1.46 & 2.09 & ns & 6.59 & 1.63 & 4.34 & 0.76 \\
\hline
\end{tabular}

${ }^{a}$ Plant height (taken from 10 random plants in each replication)

${ }^{\mathrm{b}}$ Growth duration (taken from whole population of each replication)

${ }^{\mathrm{c}}$ Panicle length (taken from 10 random panicles of each replication)

${ }^{\mathrm{d}}$ Effective tillers per plant (taken from 10 random hills of each replication)

${ }^{\mathrm{e}}$ Spikelet fertility (taken from 10 random panicles of each replication)

f Thousand-grain weight (taken from random 1000 filled grains of each replication)

${ }^{\mathrm{g}}$ Grain yield (taken from $10 \mathrm{~m}^{2}$ area of each replication)

${ }^{\mathrm{h}} \mathrm{BC}_{4} \mathrm{~F}_{2}$ 
Table 2. Recovery parameters of the tested Sub1 lines after de-submergence in T. Aman 2014 season at the submergence tank of the Plant Breeding Division, BRRI, Gazipur-1701. The duration of flooding was $18 \mathrm{~d}$. Data were mean of three replicates. The survival data was taken at $5 \mathrm{~d}$ after de-submergence and recovery status was evaluated $30 \mathrm{~d}$ of de-submergence. Percentage elongation and percentage increase in dry matter were taken from 5 plants of each replication.

Percentage survival was calculated from all the individuals of each replication.

\begin{tabular}{|c|c|c|c|c|c|c|}
\hline SI\# & Designation & $\begin{array}{c}\% \\
\text { elongation }\end{array}$ & $\begin{array}{l}\text { \% increase in } \\
\text { dry matter }\end{array}$ & \% survival & $\begin{array}{l}\text { SES }^{\text {a }} \\
\text { Score }\end{array}$ & $\begin{array}{c}\text { Recovery } \\
\text { Status }\end{array}$ \\
\hline 1. & BR157-12-2-37-13-71-26 & 6.6 & 22.2 & 71.6 & 4 & Very good \\
\hline 2. & BR157-12-2-37-13-71-32 & 12.0 & 39.8 & 66.6 & 5 & Very good \\
\hline 3. & BR157-12-2-37-13-71-38 & 12.0 & 73.8 & 66.5 & 5 & Very good \\
\hline 4. & BR157-12-2-37-13-71-41 & 11.5 & 50.0 & 86.8 & 3 & Very good \\
\hline 5. & BR157-12-2-37-13-71-46 & 14.3 & 16.6 & 62.3 & 5 & Very good \\
\hline 6. & BR157-12-2-37-13-17-27 & 11.7 & 55.2 & 73.2 & 4 & Very good \\
\hline 7. & BR157-12-2-37-13-17-32 & 3.0 & 6.7 & 65.4 & 5 & Very good \\
\hline 8. & BR157-12-2-37-13-17-36 & 9.1 & 33.9 & 70.5 & 4 & Very good \\
\hline 9. & BR157-12-2-37-13-17-39 & 17.7 & 53.1 & 66.5 & 5 & Very good \\
\hline 10. & BR157-12-2-37-13-17-41 & 13.1 & 43.5 & 64.9 & 5 & Very good \\
\hline 11. & BR157-12-2-37-13-15-25 & 13.6 & 30.2 & 72.7 & 4 & Very good \\
\hline 12. & BR157-12-2-37-13-15-30 & 11.4 & 108.4 & 83.0 & 3 & Very good \\
\hline 13. & BR157-12-2-37-13-15-35 & 10.0 & 54.1 & 68.3 & 5 & Very good \\
\hline 14. & BR157-12-2-37-13-15-40 & 11.4 & 46.3 & 87.7 & 3 & Very good \\
\hline 15. & BR157-12-2-37-13-15-42 & 0.8 & 12.1 & 77.7 & 4 & Very good \\
\hline 16. & BRRI dhan $33(\mathrm{Ck})$ & 21.0 & 71.9 & 75.2 & 5 & Fair \\
\hline 17. & BRRI dhan 44(Ck) & 91.8 & 89.1 & 48.6 & 6 & Fair \\
\hline 18. & BRRI dhan 49 (Ck) & 99.4 & 85.4 & 85.1 & 5 & Fair \\
\hline 19. & BRRI dhan $51(\mathrm{Ck})$ & 5.1 & 26.3 & 79.9 & 4 & Very good \\
\hline 20. & BRRI dhan52 (Ck) & 13.5 & 50.2 & 82.6 & 3 & Very good \\
\hline 21. & IR64-Sub1 & 17.5 & 84.2 & 73.3 & 4 & Very good \\
\hline 22. & Ciherang-Sub1 & 16.3 & 114.0 & 94.7 & 2 & Very good \\
\hline 23. & FR13(A) & 23.6 & 114.2 & 94.7 & 2 & Very good \\
\hline \multicolumn{2}{|c|}{ LSD at 0.05} & 17.04 & 27.08 & 16.28 & & \\
\hline \multicolumn{2}{|c|}{ Correlation with \% survival } & $-0.150 \mathrm{~ns}$ & $-0.150 \mathrm{~ns}$ & & & \\
\hline
\end{tabular}

${ }^{a}$ Standard evaluation system

${ }^{\mathrm{b}} \mathrm{BC}_{4} \mathrm{~F}_{3}$

${ }^{\mathrm{c}}$ Tested lines in bold font had good survival and excellent recovery 
Table 3. Physical and chemical properties of rice grains and kernels of BRRI dhan33-Sub1 lines along with standard check varieties.

Data were means of three replicates.

\begin{tabular}{|c|c|c|c|c|c|c|c|c|c|c|c|c|c|c|c|}
\hline $\begin{array}{l}\text { S1 } \\
\#\end{array}$ & Variety/Line & $\begin{array}{c}\text { Milling } \\
\text { recovery } \\
(\%)\end{array}$ & $\begin{array}{l}\text { Head } \\
\text { rice } \\
\text { yield } \\
(\%)\end{array}$ & $\begin{array}{l}\text { Appear } \\
\text { ance }\end{array}$ & $\begin{array}{c}\text { Chalki } \\
\text { ness }^{\mathrm{a}}\end{array}$ & $\begin{array}{c}\text { Length } \\
\text { (L) } \\
(\mathrm{mm})\end{array}$ & $\begin{array}{c}\text { Breadth } \\
\text { (B) } \\
(\mathrm{mm})\end{array}$ & $\begin{array}{l}\mathrm{L} / \mathrm{B} \\
\text { ratio }\end{array}$ & $\begin{array}{c}\text { Size } \\
\text { and } \\
\text { shape }^{b}\end{array}$ & $\begin{array}{c}\text { Alkali } \\
\text { spreading } \\
\text { Value }\end{array}$ & $\begin{array}{l}\text { Amy } \\
\text { lose } \\
(\%)\end{array}$ & $\begin{array}{l}\text { Protein } \\
(\%)\end{array}$ & $\begin{array}{l}\text { Cooking } \\
\text { time } \\
\text { (min.) }\end{array}$ & $\mathrm{ER}^{\mathrm{c}}$ & $\mathrm{IR}^{\mathrm{d}}$ \\
\hline 1. & $\begin{array}{l}\text { BR 9157-12-2- } \\
37-13-15-25^{\mathrm{e}}\end{array}$ & 71.6 & 51.2 & Good & $\mathrm{Wb}_{5}$ & 5.4 & 2.5 & 2.4 & SM & 3.5 & 26.4 & 8.0 & 19.3 & 1.4 & 2.5 \\
\hline 2. & $\begin{array}{l}\text { BR 9157-12-2- } \\
37-13-15-30\end{array}$ & 71.0 & 65.0 & Good & $\mathrm{Wb}_{5}$ & 5.4 & 2.5 & 2.2 & SM & 4.8 & 26.8 & 7.6 & 18.3 & 1.8 & 2.4 \\
\hline 3. & $\begin{array}{l}\text { BR 9157-12-2- } \\
37-13-17-27\end{array}$ & 71.9 & 58.0 & Good & $\mathrm{Wb}_{5}$ & 5.5 & 2.6 & 2.1 & SM & 4.3 & 26.9 & 7.4 & 18.3 & 1.6 & 2.4 \\
\hline 4. & $\begin{array}{l}\text { BR 9157-12-2- } \\
37-13-17-32\end{array}$ & 71.5 & 65.6 & Good & $\mathrm{Wb}_{5}$ & 5.4 & 2.5 & 2.1 & SM & 5.0 & 26.6 & 8.3 & 18.3 & 1.4 & 2.4 \\
\hline 5. & $\begin{array}{l}\text { BR 9157-12-2- } \\
37-13-71-32\end{array}$ & 70.7 & 51.9 & Good & $\mathrm{Wb}_{5}$ & 5.3 & 2.5 & 2.1 & SM & 4.4 & 26.2 & 7.5 & 19.0 & 1.4 & 2.4 \\
\hline 6. & $\begin{array}{l}\text { BR 9157-12-2- } \\
37-13-71-41\end{array}$ & 71.4 & 65.1 & Good & $\mathrm{Wb}_{5}$ & 5.4 & 2.5 & 2.1 & SM & 5.0 & 25.4 & 8.5 & 18.3 & 1.7 & 3.1 \\
\hline 7. & BRRI dhan33 & 70.5 & 49.0 & Good & $\mathrm{Wb}_{9}$ & 5.4 & 2.5 & 2.1 & SM & 4.5 & 27.8 & 6.6 & 20.0 & 1.3 & 3.1 \\
\hline 8. & BRRI dhan52 & 74.0 & 56.0 & Good & $\operatorname{Tr}$ & 5.7 & 2.7 & 2.1 & IM & 6.0 & 26.8 & 7.3 & 19.3 & 1.5 & 2.8 \\
\hline \multicolumn{2}{|c|}{ LSD at $16 \mathrm{df}$} & 0.56 & 2.35 & & & 0.17 & 0.08 & $\mathrm{~ns}^{\mathrm{f}}$ & & 0.39 & 0.48 & 0.21 & 0.41 & 0.11 & 0.43 \\
\hline
\end{tabular}

${ }^{\mathrm{a}} \mathrm{Tr}=$ Translucent, $\mathrm{Wb}=\mathrm{White}$ belly, $\mathrm{Wb}_{5}=10-20 \%$ endosperm chalkiness, $\mathrm{Wb}_{9} \geq 20 \%$ endosperm chalkiness

${ }^{\mathrm{b}} \mathrm{SM}=$ Short Medium, IM=Intermediate Medium,

${ }^{\mathrm{c}}$ Elongation ratio

${ }^{\mathrm{d}}$ Imbibition ratio

${ }^{\mathrm{e}} \mathrm{BC}_{4} \mathrm{~F}_{3}$

f non-significant 
Table 4. Performance of submergence-tolerant lines and selected references and checks under non-flooded conditions. Data were averages of three locations (Gazipur, Rangpur, and Nilphamari) in Bangladesh in T. aman 2014. Plant height was taken from 10 random plants of each replication. Panicles/plant, filled grains/panicle and sterility\% were taken from 10 random plants of each replications. Grain yield (t/ha) was recorded from $10 \mathrm{~m}^{2}$ area and the data was adjusted at $14 \%$ moisture content.

\begin{tabular}{|l|l|c|c|c|c|c|c|}
\hline Sl\# & Designation & $\begin{array}{c}\text { Growth } \\
\text { Duration } \\
(\text { days })\end{array}$ & $\begin{array}{c}\text { Plant } \\
\text { Height } \\
(\mathrm{cm})\end{array}$ & $\begin{array}{c}\text { Panicles/ } \\
\text { plant }\end{array}$ & $\begin{array}{c}\text { Filled } \\
\text { Grains/ } \\
\text { panicle }\end{array}$ & $\begin{array}{c}\text { Sterility\% } \\
\text { Grain Yield } \\
\text { (t/ha) }\end{array}$ \\
\hline 1. & IR10F365 & 125 & 114.9 & 10 & 99 & 25.8 & 4.4 \\
\hline 2. & IR09F130 & 124 & 117.4 & 9 & 118 & 18.7 & 4.5 \\
\hline $\mathbf{3 .}$ & BR9157-12-2-37-13-71-32 & $\mathbf{1 1 9}$ & $\mathbf{1 0 8 . 7}$ & $\mathbf{7}$ & $\mathbf{1 1 4}$ & $\mathbf{2 4 . 1}$ & $\mathbf{4 . 8}$ \\
\hline 4. & BR9157-12-2-37-13-17-27 & 119 & 105.7 & 7 & 128 & 21.1 & 4.6 \\
\hline $\mathbf{5 .}$ & BR9157-12-2-37-13-15-30 & $\mathbf{1 1 8}$ & $\mathbf{1 0 5 . 6}$ & $\mathbf{7}$ & $\mathbf{1 1 1}$ & $\mathbf{2 3 . 7}$ & $\mathbf{4 . 8}$ \\
\hline 6. & BR9157-12-2-37-13-15-25 & 119 & 108.6 & 7 & 121 & 22.8 & 4.5 \\
\hline 7. & BINA dhan11(Ck) & 118 & 105.8 & 8 & 81 & 29.9 & 4.0 \\
\hline 8. & BRRI dhan33(Ck) & 119 & 105.9 & 8 & 116 & 21.8 & 4.0 \\
\hline & LSD (0.05) & 1.17 & 4.36 & 0.93 & 16.2 & 4.37 & 0.31 \\
\hline
\end{tabular}

${ }^{\mathrm{a}}$ Tested lines in bold font had very good recovery status and SES score of 3.

${ }^{\mathrm{b}} \mathrm{BC}_{4} \mathrm{~F}_{3}$ 
Table 5. Performance of tested lines under flooded conditions. Data were averages of two locations in Bangladesh, Lalmonirhat and Rangpur, in T. aman 2014. There were 3 replications in each location. At Lalmonirhat, there were two flash flood events for 15 and $9 \mathrm{~d}$ (Table A.7). There was a period of $23 \mathrm{~d}$ between the two events, and the average depth of flood water was $110-120 \mathrm{~cm}$. Sixteen d of controlled submergence with a water depth of $80 \mathrm{~cm}$ was imposed at BRRI, Rangpur.

\begin{tabular}{|l|l|c|c|c|c|c|c|c|}
\hline Sl\# & Designation & $\begin{array}{c}\text { Growth } \\
\text { duration } \\
\text { (days) }\end{array}$ & $\begin{array}{c}\text { Plant } \\
\text { height } \\
(\mathrm{cm})\end{array}$ & $\begin{array}{c}\text { Panicle/ } \\
\text { plant }\end{array}$ & $\begin{array}{c}\text { Filled } \\
\text { grains/ } \\
\text { panicle }\end{array}$ & $\begin{array}{c}\% \\
\text { sterility }\end{array}$ & $\begin{array}{c}\text { Grain } \\
\text { yield } \\
\text { (t/ha) }\end{array}$ & $\begin{array}{c}\text { \% } \\
\text { survival }\end{array}$ \\
\hline 1. & IR10F365 & 152 & 86.6 & 8 & 91 & 23.0 & 3.6 & 86.4 \\
\hline 2. & IR09F130 & 149 & 102.9 & 8 & 141 & 14.0 & 3.8 & 93.1 \\
\hline 3. & BR9157-12-2-37-13-71-32 & 143 & 91.6 & 7 & 135 & 11.2 & 3.7 & 90.0 \\
\hline 4. & BR9157-12-2-37-13-17-27 & 143 & 93.6 & 7 & 126 & 10.2 & 3.8 & 93.1 \\
\hline 5. & BR9157-12-2-37-13-15-30 & 142 & 92.0 & 7 & 123 & 16.5 & 3.7 & 95.2 \\
\hline 6. & BR9157-12-2-37-13-15-25 & 142 & 91.5 & 7 & 115 & 16.1 & 3.8 & 93.9 \\
\hline 7. & BINA dhan11(Ck) & 140 & 77.1 & 7 & 83 & 23.4 & 3.3 & 96.3 \\
\hline 8. & BRRI dhan33(Ck) & 143 & 89.0 & 9 & 48 & 15.2 & 1.5 & 46.6 \\
\hline LSD (0.05) & 28.78 & 23.95 & ns & 26.66 & 5.75 & 0.83 & 20.39 \\
\hline
\end{tabular}

\section{${ }^{\mathrm{a}} \mathrm{BC} 4 \mathrm{~F} 3$}

Entry number 1 to 7 have $S U B 1$, only BRRI dhan33 does not have $S U B 1$ 


\section{BRRI dhan33}

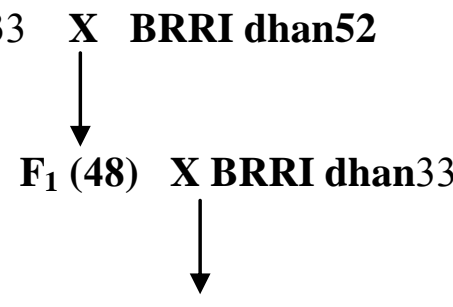

$\mathrm{BC}_{1} \mathrm{~F}_{1}$ (137) X BRRI dhan 33

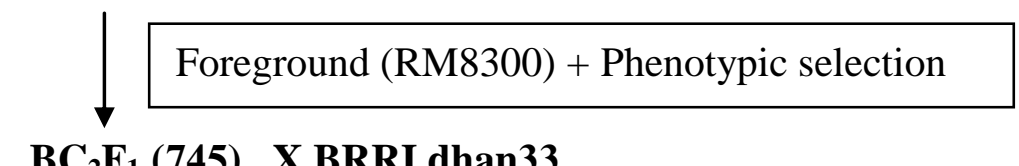

$\mathrm{BC}_{2} \mathrm{~F}_{1}(745) \quad \mathrm{X}$ BRRI dhan 33

Foreground (RM8300) + Phenotypic selection

$\mathrm{BC}_{3} \mathrm{~F}_{1}$ (307) X BRRI dhan33

Foreground (RM8300) + Phenotypic selection

$\mathrm{BC}_{4} \mathbf{F}_{1}$ (716)

Foreground (Sub1C173) + Phenotypic selection

\section{$\mathrm{BC}_{4} \mathbf{F}_{2}(\mathbf{1 2 0 0})$}

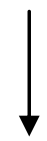

Foreground, Recombinant \& Background Selection

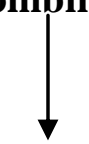

\section{Plants Selected $(15,17,71$ and 82)}

Figure 1. Marker assisted backcrossing scheme used indicating "Foreground and Phenotypic" selection steps. The number of plants at each step to develop BRRI dhan33-Sub1 lines is shown. 


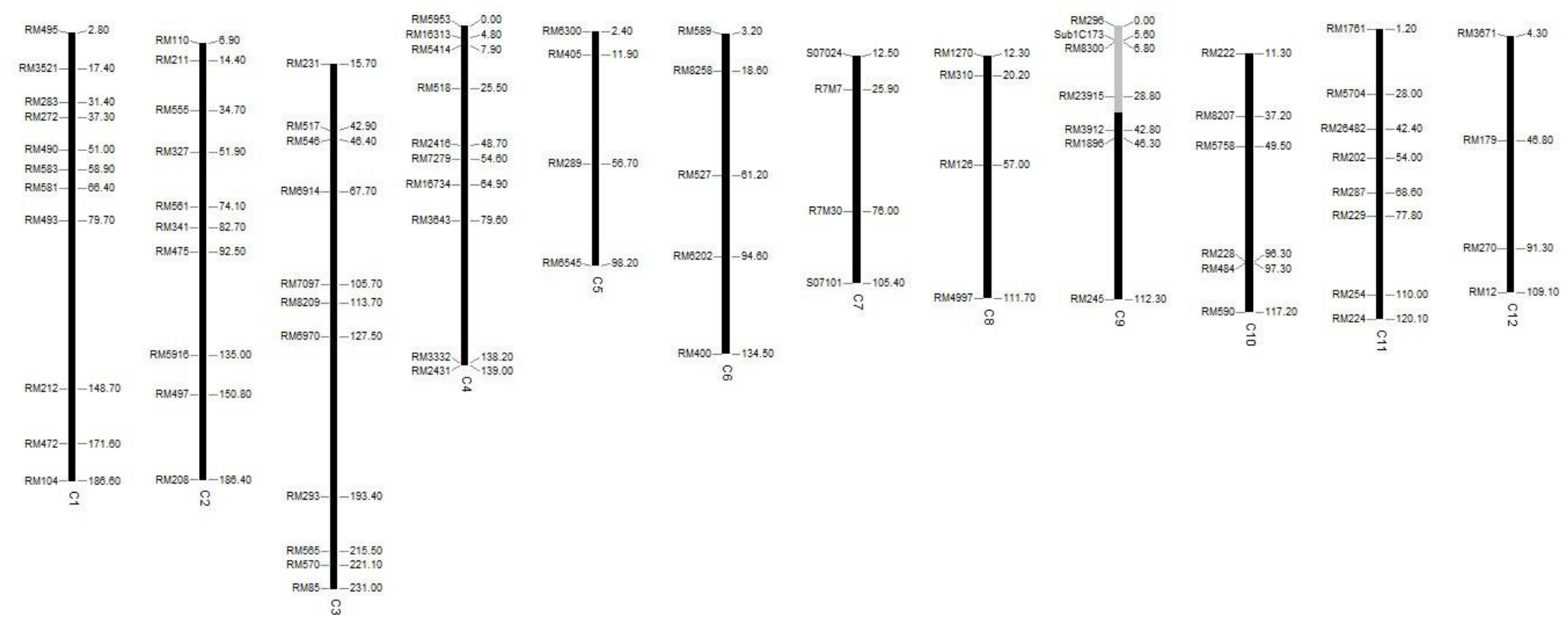

Ind no:1 [BR33-Sub1] - BR9157-12-2-37-13-17-25 
Table A.1. List of polymorphic markers of all 12 chromosomes used in background selection in the development of BR dhan33-Sub1 lines.

\begin{tabular}{|l|l|l|l|l|l|}
\hline Chr 1 & Chr 2 & Chr 3 & Chr 4 & Chr 5 & Chr 6 \\
\hline RM495 & RM110 & RM231 & RM5953 & RM6300 & RM589 \\
\hline RM3521 & RM211 & RM517 & RM16313 & RM405 & RM8258 \\
\hline RM283 & RM555 & RM546 & RM5414 & RM289 & RM527 \\
\hline RM272 & RM327 & RM6914 & RM518 & RM6545 & RM6202 \\
\hline RM490 & RM561 & RM7097 & RM2416 & & RM400 \\
\hline RM583 & RM341 & RM8209 & RM7279 & & \\
\hline RM581 & RM475 & RM6970 & RM16734 & & \\
\hline RM493 & RM5916 & RM293 & RM3643 & & \\
\hline RM212 & RM497 & RM565 & RM3332 & & \\
\hline RM472 & RM208 & RM570 & RM2431 & & Chr 12 \\
\hline RM104 & & RM85 & & & RM3671 \\
\hline Chr 7 & Chr 8 & Chr 9 & Chr 10 & Chr 11 & RM179 \\
\hline S07024 & RM1270 & RM296 & RM222 & RM1761 & RM270 \\
\hline R7M7 & RM310 & Sub1C173 & RM8207 & RM5704 & RM12 \\
\hline R7M30 & RM126 & RM8300 & RM5758 & RM26482 & \\
\hline S07101 & RM4997 & RM23915 & RM228 & RM202 & \\
\hline & & RM3912 & RM484 & RM287 & \\
\hline & & RM1896 & RM590 & RM229 & \\
\hline & & RM245 & & RM254 & \\
\hline & & & & & \\
\hline
\end{tabular}


Table A.2. Range of light intensity, $\mathrm{pH}$ and temperature of water during submergence period to check the performance of submergence-tolerant lines along with selected references and checks under non-flooded conditions, BRRI, Gazipur, T. aman 2014.

\begin{tabular}{|c|c|c|c|c|}
\hline \multirow[t]{2}{*}{ Water level } & \multicolumn{2}{|c|}{ Light intensity $\left(\mathrm{w} / \mathrm{m}^{2}\right)$} & Water $\mathrm{pH}$ & Water temperature $\left({ }^{\circ} \mathrm{C}\right)$ \\
\hline & Before turbidity & After turbidity & \multirow[t]{4}{*}{ 7.1-7.5 } & \multirow[t]{4}{*}{$30-31.5$} \\
\hline $\begin{array}{l}\text { Upper level } \\
\text { (above water } \\
\text { surface) }\end{array}$ & \multicolumn{2}{|c|}{$100-130$} & & \\
\hline $\begin{array}{l}\text { Mid-level } \\
\text { ( } 30 \mathrm{~cm} \\
\text { below water } \\
\text { surface) }\end{array}$ & $20-27$ & $1-1.9$ & & \\
\hline $\begin{array}{l}\text { Lower level } \\
\text { ( } 75 \mathrm{~cm} \\
\text { below water } \\
\text { surface) }\end{array}$ & $2.5-6.6$ & $0-0.023$ & & \\
\hline
\end{tabular}


Table A.3. Criteria for recovery status after submergence stress. Recovery data was taken 30 days after submergence.

\begin{tabular}{|l|l|}
\hline Recovery status & Criteria \\
\hline Excellent & $\begin{array}{l}\text { Highly satisfactory growth and } \\
\text { tillering, erect dark green leaves }\end{array}$ \\
\hline Very good & $\begin{array}{l}\text { Satisfactory growth and tillering, } \\
\text { erect green leaves }\end{array}$ \\
\hline Good & $\begin{array}{l}\text { Normal growth and tillering, erect } \\
\text { green leaves }\end{array}$ \\
\hline Fair & $\begin{array}{l}\text { Low growth and tillering, droopy, } \\
\text { pale green leaves }\end{array}$ \\
\hline Poor & $\begin{array}{l}\text { Very low growth and tillering, long } \\
\text { pale green leaves }\end{array}$ \\
\hline
\end{tabular}


Table A.4. Standard evaluation system (SES) for survival after submergence. Survival data was taken 5 days after submergence.

\begin{tabular}{|l|l|}
\hline Scores & \% Survival \\
\hline 1 & 100 \\
\hline 2 & $90-99$ \\
\hline 3 & $80-89$ \\
\hline 4 & $70-79$ \\
\hline 5 & $60-69$ \\
\hline 6 & $50-59$ \\
\hline 7 & $40-49$ \\
\hline 8 & $30-39$ \\
\hline 9 & $<30$ \\
\hline
\end{tabular}


Table A.5. Results of background selection, Observational Trial ( $\mathrm{BC}_{4} \mathrm{~F}_{3}$ generation), $\mathrm{T}$. Aman 2013. Type A refers to the eight lines possessing homozygous recipient alleles for 80 background markers for non-carrier chromosomes; homozygous donor alleles for RM296, Sub1C173, RM8300 and RM23915 for chromosome 9. Type B refers to the six lines had homozygous recipient alleles for 78 background markers for non-carrier chromosomes; homozygous donor alleles for RM296, Sub1C173, RM8300, RM23915, RM3912 and RM1896 for chromosome 9.

\begin{tabular}{|l|c|c|}
\hline Allele & Type A lines $^{\mathrm{a}}$ & Type B lines $^{\mathrm{b}}$ \\
\hline A (homozygous recipient alleles) & 80 & 78 \\
\hline H (heterozygous alleles) & 0 & 0 \\
\hline B (donor alleles) & 4 & 6 \\
\hline \%A & 95.24 & 90.7 \\
\hline \%Recipient allele & 95.24 & 90.7 \\
\hline
\end{tabular}

aBR9157-12-2-37-13-15-25, BR9157-12-2-37-13-15-30, BR9157-12-2-37-13-15-35, BR915712-2-37-13-15-40, BR9157-12-2-37-13-15-42, BR9157-12-2-37-13-17-27, BR9157-12-2-37-1317-39 and BR9157-12-2-37-13-17-41

bBR9157-12-2-37-13-17-32, BR9157-12-2-37-13-17-36, BR9157-12-2-37-13-71-26, BR915712-2-37-13-71-32, BR9157-12-2-37-13-71-38 and BR9157-12-2-37-13-71-41 
Table A.6. Different alleles of the Sub1-region markers among the BRRI dhan33-Sub1 lines. 'A' represents the recipient's allele, BRRI dhan 33; 'B' represents the donor's allele, BRRI dhan52.

\begin{tabular}{|l|l|l|l|l|l|l|l|l|l|}
\hline Marker & $\begin{array}{l}\text { Position } \\
(\mathrm{Mb})\end{array}$ & G1 & G2 & G3 & G4 & G5 & G6 & $\begin{array}{l}\text { BRRI } \\
\text { dhan33 }\end{array}$ & $\begin{array}{l}\text { BRRI } \\
\text { dhan52 }\end{array}$ \\
\hline RM8300 & 5.17 & B & B & B & B & B & B & A & B \\
\hline RM23843 & 6.21 & B & B & B & B & B & B & A & B \\
\hline SC41 & 6.95 & B & B & B & B & B & B & A & B \\
\hline RM23901 & 6.99 & B & B & B & B & B & B & A & B \\
\hline ART5 & $\begin{array}{l}\text { Sub1C } \\
\text { promoter }\end{array}$ & B & B & B & B & B & B & A & B \\
\hline Sub1BC1 & $\begin{array}{l}\text { Between } \\
\text { Sub1B } \\
\text { and C }\end{array}$ & B & B & B & B & B & B & A & B \\
\hline Sub1BC2 & $\begin{array}{l}\text { Between } \\
\text { Sub1B } \\
\text { and C }\end{array}$ & B & B & B & B & B & B & A & B \\
\hline Sub1BC3 & $\begin{array}{l}\text { Between } \\
\text { Sub1B } \\
\text { and C }\end{array}$ & B & B & B & B & B & B & A & B \\
\hline Sub1C173 & $\begin{array}{l}\text { Exon of } \\
\text { Sub1C }\end{array}$ & B & B & B & B & B & B & A & B \\
\hline GnS2 & $\begin{array}{l}\text { Exon of } \\
\text { Sub1A }\end{array}$ & B & B & B & B & B & B & A & B \\
\hline SC23 & 7.22 & B & B & B & B & B & B & A & B \\
\hline RM23917 & 7.31 & B & B & B & B & B & B & A & B \\
\hline RM23915 & 7.31 & B & B & B & B & B & B & A & B \\
\hline RM23902 & 7.58 & B & B & B & B & B & B & A & B \\
\hline RM296 & 10.79 & B & B & B & B & B & A & A & B \\
\hline RM3912 & 10.83 & A & A & A & A & A & A & A & B \\
\hline $\begin{array}{l}\text { Introgression } \\
\text { size (Mb) }\end{array}$ & & $\mathbf{5 . 6 2}$ & $\mathbf{5 . 6 2}$ & $\mathbf{5 . 6 2}$ & $\mathbf{5 . 6 2}$ & $\mathbf{5 . 6 2}$ & $\mathbf{2 . 4 1}$ & & \\
\hline
\end{tabular}

${ }^{\mathrm{a}} \mathrm{G} 1=\mathrm{BR}$ 9157-12-2-37-13-15-25, G2=BR 9157-12-2-37-13-15-30 (the same as BR 9157-12-2-

37-13-15-40), G3=BR 9157-12-2-37-13-17-27, G4=BR 9157-12-2-37-13-17-32, G5=BR 915712-2-37-13-71-32, G6=BR 9157-12-2-37-13-71-41 
Table A.7. Status of flash flood at different locations of Bangladesh in T. aman 2014.

\begin{tabular}{|l|l|c|c|c|c|}
\hline Locations & Flood status & $\begin{array}{c}\text { Date of } \\
\text { Submergence }\end{array}$ & $\begin{array}{c}\text { Date of } \\
\text { desubmergence }\end{array}$ & $\begin{array}{c}\text { Duration of } \\
\text { submergence }\end{array}$ & $\begin{array}{c}\text { Average flood } \\
\text { water height } \\
(\mathrm{cm})\end{array}$ \\
\hline Lalmonirhat & $\begin{array}{l}\text { First Flood } \\
\text { (natural) }\end{array}$ & 15 August 2014 & 29 August 2014 & 15 days & 110 \\
\cline { 2 - 5 } & $\begin{array}{l}\text { Second } \\
\text { Flood } \\
\text { (natural) }\end{array}$ & $\begin{array}{c}\text { 22 September } \\
2014\end{array}$ & 30 September 2014 & 9 days & 120 \\
\hline Rangpur & $\begin{array}{l}\text { Controlled } \\
\text { submergence }\end{array}$ & 14 August 2014 & 30 August 2014 & 16 days & 80 \\
\hline
\end{tabular}




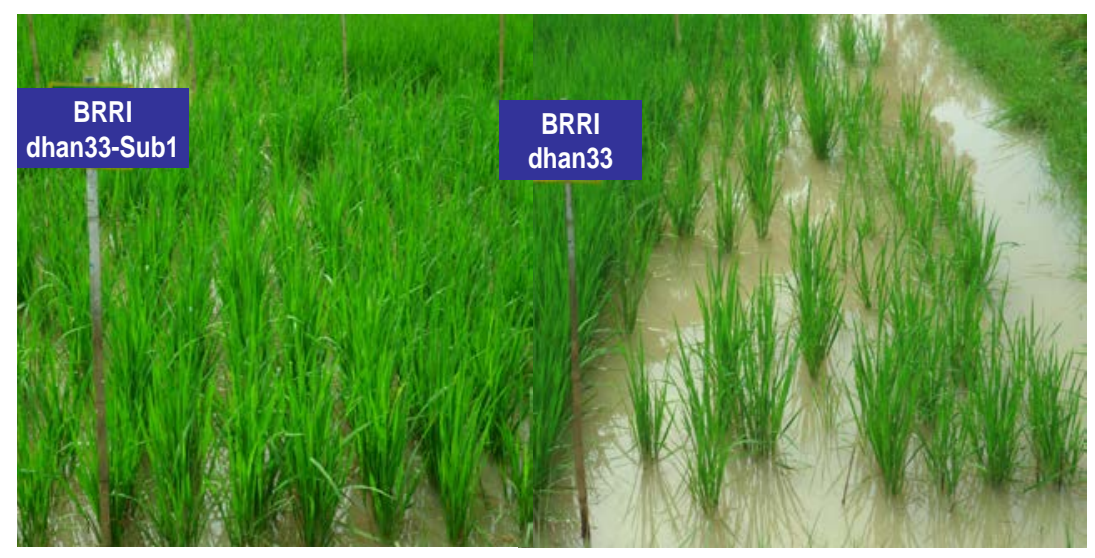

Figure A.1. Survival of BRRI dhan33-Sub1 line (BR9157-12-2-37-13-17) and BRRI dhan33 after $16 \mathrm{~d}$ of controlled submergence at BRRI, Gazipur, T. aman 2013. The survival of BRRI dhan33 (recurrent parent check) was 22.1\% whereas that of BRRI dhan33-Sub1 line (BR915712-2-37-13-17) was $88.9 \%$. 

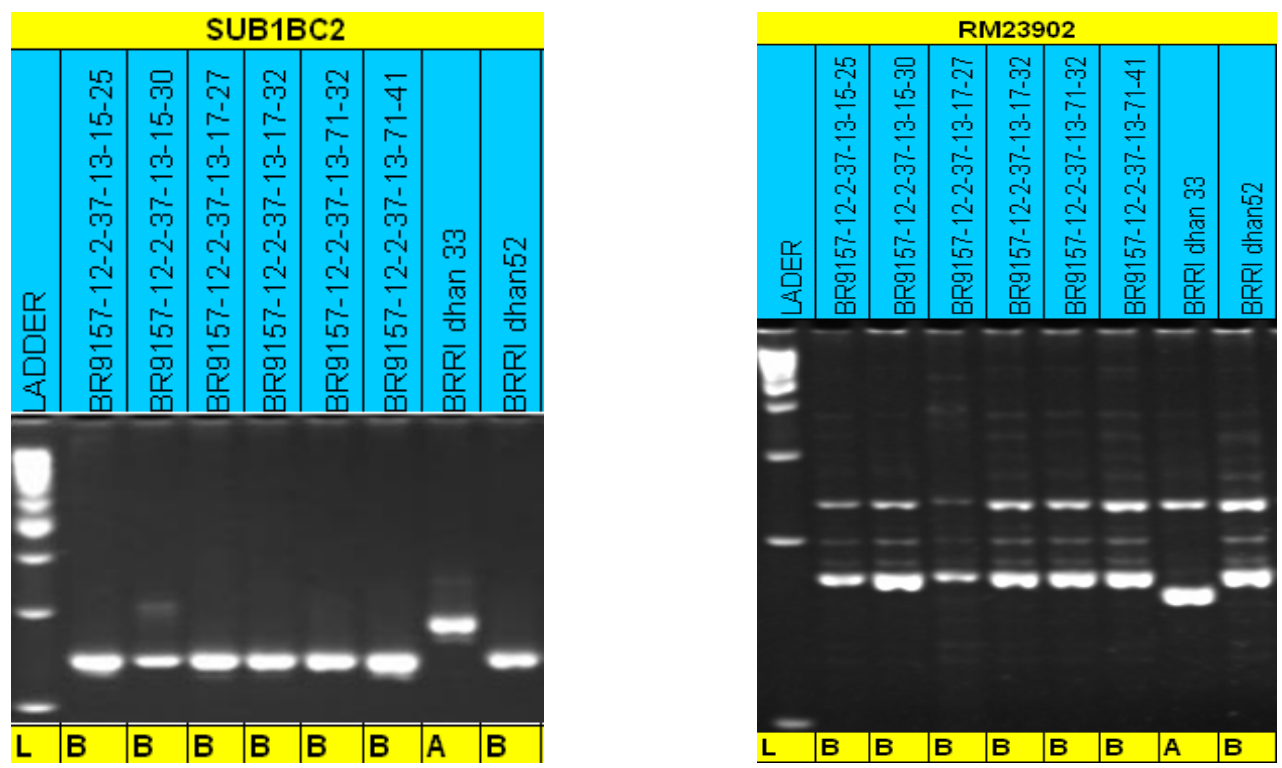

Figure A.2. Examples of different alleles of SUB1BC2 and RM23902 markers among the BRRI dhan33-Sub1 lines. 'A' refers to BRRI dhan33, the recurrent parent's alleles, while 'B' refers to BRRI dhan52, the donor parent's allele. It showed that all the BRRI dhan33-Sub1 lines already have fixed donor alleles. 